
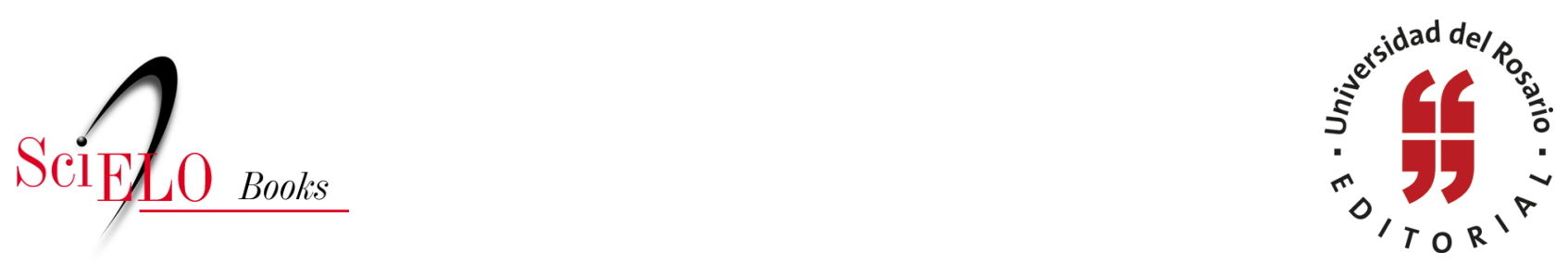

\title{
Preguntas de investigación e hipótesis
}

\author{
Mayra Alejandra Umaña Cifuentes
}

UMAÑA CIFUENTES, M.A. Preguntas de investigación e hipótesis. In: Del este de Europa al sur de América: Migraciones soviéticas y postsoviéticas a la ciudad de Bucaramanga, Santander [online]. Bogotá: Editorial Universidad del Rosario, 2015, pp. 17-20. Opera prima collection. ISBN: 978-958738-595-3. https://doi.org/10.7476/9789587385953.0002.

International license.

Todo o conteúdo deste trabalho, exceto quando houver ressalva, é publicado sob a licença Creative Commons Atribição 4.0.

Todo el contenido de esta obra, excepto donde se indique lo contrario, está bajo licencia de la licencia $\underline{\text { Creative }}$ Commons Reconocimento 4.0 . 


\section{Preguntas de investigación e hipótesis}

En esta investigación daremos respuesta a dos preguntas fundamentales que nos permitirán entender de manera profunda el proceso migratorio de los ciudadanos de las ex repúblicas soviéticas y serán la guía que estructurará este documento. La primera pregunta que nos compete es: ¿cuáles fueron los factores que motivaron la migración de ciudadanos provenientes de las naciones soviéticas y postsoviéticas a Colombia y Bucaramanga? En segunda medida, nos interesa indagar por cómo estos inmigrantes se integraron a la ciudad una vez se establecieron. Igualmente, hemos establecido como nuestra hipótesis principal la siguiente: el capital humano e intelectual que detentaban estos sujetos al llegar les permitirían integrarse a las élites intelectuales de la ciudad de Bucaramanga. Además, la alta cualificación de estos sujetos les permitiría una integración menos traumática y en esferas altas de la sociedad receptora, sin pasar por procesos de marginación.

Antes de proseguir, tenemos que enfatizar el hecho que es necesario superar: la falsa creencia de que en Colombia no existe la inmigración ni los inmigrantes, por el hecho de que no sucediera a gran escala, como sí sucedió en Estados Unidos y en países de la región como Brasil o Argentina. Este preconcepto se evidencia de dos formas: primero, en el 
hecho de que la producción académica suela centrarse en las personas que dejan el país y no en quienes llegan, y segundo, en el hecho de que la literatura académica sobre el tema obedezca más a investigaciones de tipo histórico, enfocadas en la caracterización de migraciones más antiguas y de mayor volumen, como la migración alemana a Santander y la sirio libanesa en el Caribe.

Por otra parte, las investigaciones sobre inmigraciones actuales se concentran en los grupos más notorios como los venezolanos y ecuatorianos. En este mismo sentido, los análisis no van más allá de la caracterización de la población, dejando de lado en el mundo académico grupos más pequeños, que aunque menores en cantidad, también hacen parte importante de las dinámicas migratorias y del desarrollo de las regiones.

La migración a la que aquí nos referimos hace parte de estos pequeños grupos que han llegado al país en las últimas décadas. Por tanto, la pretensión de este estudio es visibilizar esta población, además de descubrir cómo fueron sus procesos migratorios y describir cómo ha sido el proceso de integración a la ciudad receptora, a decir Bucaramanga. $\mathrm{Al}$ ser poca la información que se presenta sobre este grupo de inmigrantes en nuestro país, vale la pena explorar varios asuntos relacionados con sus procesos migratorios y de integración en la ciudad, con el fin de presentar un panorama amplio de los procesos migratorios de este grupo y sentar las bases para estudios ulteriores.

Suele afirmarse que no existe una teoría unificada sobre la migración. En este estudio asumimos esa misma postura. 
Además, veremos el proceso migratorio como un continuum temporal que inicia antes del hecho mismo de migrar y no concluye con el asentamiento de las personas, por lo cual utilizaremos no una teoría, sino una serie de teorías que nos ayuden a interpretar las diversas etapas del proceso. De la misma manera, el trabajo que presentamos aquí trata de seguir el proceso mismo que tuvieron los inmigrantes y se estructura de esa forma, por tanto este escrito se compone de tres capítulos, que a seguir desglosaremos.

El primer capítulo se divide en dos partes. En la primera, nos concentraremos en explicar la historia migratoria de Colombia y su ubicación dentro del panorama latinoamericano para después concentrarnos en explicar la inmigración que tuvo específicamente el departamento de Santander. Esto, con el fin de exponer la importancia que han tenido los inmigrantes en el desarrollo de la región y el lugar que han ocupado en el espacio social. En la segunda parte, nos enfocaremos en explicar la historia migratoria de la Unión de Repúblicas Socialistas Soviéticas -URss-con el fin de entender cómo y cuáles han sido las migraciones a través de su historia y especialmente en el periodo de la perestroika y la posperestroika.

En el segundo capítulo, nos concentraremos en indagar cuáles son los factores que influyen en la determinación del sujeto de desplazarse, indagando las causas de la migración en diferentes niveles, observando no sólo los factores macroestructurales, sino el papel de las redes en el proceso de la migración, así como la construcción de imaginarios, inquiriendo por el papel que jugaron en el proceso migratorio. 
En el tercer y último capítulo analizaremos el proceso de integración y asimilación a la ciudad de Bucaramanga, examinando el papel que juegan las relaciones con otros sujetos en el proceso de socialización, al igual que el papel de las instituciones. Encerraremos este capítulo analizando cómo debido a toda su experiencia migratoria y a sus procesos de integración, los inmigrantes han formado un vínculo identitario con el país y con la ciudad que coexiste con su modo de ser soviético. Para finalizar, debemos mencionar que, ante todo, en esta investigación pretendemos dar voz a quienes vivieron el proceso migratorio, rescatando sus historias, particularidades, subjetividades y perspectivas. 